\title{
Effectiveness and safety of oral olanzapine treatment transitioned from rapid-acting intramuscular olanzapine for agitation associated with schizophrenia
}

This article was published in the following Dove Press journal:

Neuropsychiatric Disease and Treatment

\author{
Hideaki Katagiri' \\ Masanori Taketsuna ${ }^{2}$ \\ Shinpei Kondo 3 \\ Kenta Kajimoto ${ }^{4}$ \\ Etsuko Aoi ${ }^{5}$ \\ Yuka Tanji
}

'Bio-Medicines, Medicines

Development Unit Japan, Eli Lilly Japan K.K., Kobe, Japan; ${ }^{2}$ Statistical Sciences, Medicines Development Unit Japan, Eli Lilly Japan K.K., Kobe, Japan; ${ }^{3}$ Post Marketing Study Management, Medicines Development Unit Japan, Eli Lilly Japan K.K., Kobe, Japan; ${ }^{4}$ Scientific Communications, Medicines Development Unit Japan, Eli Lilly Japan K.K., Kobe, Japan; ${ }^{5}$ Global Patient Safety Japan, Quality and Patient Safety, Eli Lilly Japan K.K., Kobe, Japan

Correspondence: Hideaki Katagiri Eli Lilly Japan K.K., Sannomiya Plaza Bldg., 7-I-5, Isogamidori, Chuo-ku, Kobe 65I-0086, Japan

$\mathrm{Tel}+8 \mathrm{I} 782429389$

Fax +81782429526

Email katagiri_hideaki@lilly.com
Objective: To assess the effectiveness and safety of oral olanzapine treatment transitioned from rapid-acting intramuscular olanzapine (RAIM) in patients with acute agitation associated with schizophrenia in a real-world clinical setting.

Methods: The postmarketing surveillance study with a 3-day observational period after the last RAIM administration was conducted (original study). Following this, an extended study was added for patients who received oral olanzapine after RAIM administration during the original study period, in order to additionally observe them for 7 days after initial RAIM administration. Effectiveness and safety from initial RAIM administration were evaluated using the Positive and Negative Syndrome Scale-Excited Component score and treatment-emergent adverse events (TEAEs), respectively.

Results: The effectiveness and safety analysis set included a total of 521 and 522 patients, respectively. A majority of patients received $10 \mathrm{mg}$ of RAIM (475/522 patients, $91.0 \%$ ). The mean \pm SD total Positive and Negative Syndrome Scale-Excited Component score was 23.6 \pm 6.2 $(\mathrm{n}=318)$ at baseline (before initial RAIM administration), $17.4 \pm 6.8(\mathrm{n}=280)$ at 2 hours after initial administration, $16.2 \pm 6.8(\mathrm{n}=246) 2$ days after final administration, 14.9 $\pm 6.2(\mathrm{n}=248) 3$ days after final administration, $13.8 \pm 5.9(n=242) 4$ days after final administration, $13.2 \pm 5.8(n=221) 7$ days after initial administration, and $13.4 \pm 6.2(\mathrm{n}=351)$ at final observation (with the last observation carried forward approach), showing that reduction in agitation seen with RAIM was sustained with oral dose of olanzapine. The most common TEAEs were dyslalia and somnolence (each event occurred in four patients), and abnormal hepatic function and constipation (occurred in three patients). One serious adverse event of sudden cardiac death occurred after transitioned to oral olanzapine with many other antipsychotic drugs.

Conclusion: In the treatment of acute agitation associated with schizophrenia, RAIM could be generally transitioned to oral olanzapine without exacerbating adverse events or losing treatment effect.

Keywords: agitation, schizophrenia , rapid-acting intramuscular olanzapine, Japan postmarketing surveillance study, PANSS-EC

\section{Introduction}

Highly agitated patients with schizophrenia or acute mania require urgent treatment to alleviate symptoms and prevent the escalation of violent or destructive behavior. While nonpharmacological interventions followed by voluntary oral medication are preferable treatment strategies, fast-acting parenteral medications may be necessary. ${ }^{1}$ 
Acutely agitated patients with schizophrenia require urgent treatment to prevent the escalation of violent or destructive behavior. ${ }^{1}$ According to the World Federation of Societies of Biological Psychiatry Guidelines, oral medication is preferable to parenteral (intramuscular or intravenous) medication to treat these patients. ${ }^{2}$ However, there are benefits to treating patients with parenteral medication, since parenteral medication can enable more rapid onset of drug action thereby leading to a faster improvement in symptoms. ${ }^{1,3,4}$

When treating agitation associated with schizophrenia, it is important for clinicians to treat patients in a way that provides a rapid decrease in patient agitation while simultaneously minimizing treatment-emergent adverse events (TEAEs). Parenteral medication can be helpful in calming agitated patients refusing oral medications. Although the oral route of administration is the preferred strategy for treatment, ${ }^{2}$ it is often necessary for the patient to be treated with parenteral medications in order to alleviate the symptoms as quickly as possible. ${ }^{1,3,5}$ However, once the symptoms are alleviated, it is important that after parenteral treatment, in order for the symptoms of agitated patients to be controlled and maintained with appropriate medications, the clinician needs to consider modes of treatment other than the parenteral route. For this reason, transitioning the patient from an intramuscular route to an oral formulation may help with long-term management of the disease. It can also improve patient adherence and compliance to treatment. ${ }^{6,7}$

It is well known that intramuscular olanzapine has a generally favorable extrapyramidal symptoms safety profile, and a similar efficacy compared to the parenteral typical antipsychotics. ${ }^{89}$ Previous clinical trials have reported a significant improvement from baseline in Positive and Negative Syndrome Scale-Excited Component (PANSS-EC) scores 2 hours after intramuscular olanzapine ${ }^{10,11}$ in patients with agitation associated with schizophrenia. In addition, previous studies have shown minimal to no incidences of treatment-emergent extrapyramidal symptoms with intramuscular olanzapine. ${ }^{8,11,12}$

The efficacy and safety of olanzapine and haloperidol during transition from intramuscular to oral therapy were evaluated in a previous study. ${ }^{13}$ The study showed that intramuscular olanzapine $10 \mathrm{mg}$ and intramuscular haloperidol $7.5 \mathrm{mg}$ effectively reduced agitation over 24 hours in acutely agitated patients with schizophrenia, and this reduction in agitation was sustained following transition from intramuscular therapy to 4 days of oral treatment $(5-20 \mathrm{mg}$ /day for both olanzapine and haloperidol). ${ }^{13}$ During the period of oral treatment, olanzapine-treated patients did not report incidences of dystonia, and patients treated with olanzapine maintained a more favorable extrapyramidal symptom safety profile compared with haloperidol. ${ }^{13}$ This study suggested that the transition from intramuscular to oral olanzapine may help to improve the treatment of acutely agitated patients with schizophrenia, and maintain the reduction in agitation in these patients.

We have previously reported the results of the observational postmarketing surveillance (PMS) study conducted in Japan to evaluate the safety and effectiveness of rapid-acting intramuscular olanzapine (RAIM) for agitation associated with schizophrenia. ${ }^{14}$ A significant improvement in the total PANSS-EC score compared with the baseline score was seen at 2 hours after initial administration of RAIM, and this reduction in agitation was maintained for 3 days since the last RAIM administration, regardless of the treatment following RAIM. There were no new safety concerns identified in the original PMS study. Moreover, we were interested in whether intramuscular olanzapine could be transitioned to oral olanzapine effectively and safely. Therefore, here we evaluate the effectiveness and safety profiles of patients who transitioned from RAIM to oral olanzapine treatment in a real-world clinical setting, which was longer than in the previous report that only included the acute period. ${ }^{14}$

\section{Methods \\ Study design}

This report includes data from the original (previously reported) and extension studies of the PMS study. The studies were observational and non interventional. The original PMS study had a 3-day observational period after the last administration of RAIM, including the initial day of administration. ${ }^{14}$ In order to observe the effectiveness and safety for the acute and maintenance treatment phases in patients who transitioned from RAIM to oral olanzapine treatment during the original PMS study, we added an additional observational period as the extension study. These patients were monitored for 7 days from the initial RAIM administration. When patients were administered additional RAIM during the observational period, this observational period was extended by another 3 days for the original PMS study, but the observational period for this extension study was extended until the end of the study period (day 7) after initial administration (Figure 1).

The studies were conducted in accordance with the Good Postmarketing Study Practice of the Pharmaceutical Affairs Law of Japan. Informed consent was not obtained 


\begin{tabular}{|l|l|l|l|l|l|l|l|}
\hline Study period & Day 1 & Day 2 & Day 3 & Day 4 & Day 5 & Day 6 & Day 7 \\
\hline Pattern 1 $(n=416)$ & RAIM & & & & & & \\
\hline Pattern 2 $(n=29)$ & RAIM & RAIM & & & & \\
\hline Pattern 3 $(n=63)$ & RAIM & RAIM & RAIM & & & & \\
\hline Others $(n=14)$ & \multicolumn{7}{|l|}{} \\
\hline
\end{tabular}

Figure I Study design.

Notes: Gray-colored table cells refer to the original study period. Not Gray (clear) table cells refer to the extension study period. "Others" includes four consecutive days of administration of RAIM and several time points of administration of RAIM not on consecutive days.

Abbreviation: RAIM, rapid-acting intramuscular olanzapine.

from these patients, since the Good Postmarketing Study Practice of the Pharmaceutical Affairs Law of Japan does not require informed consent to be obtained from patients in postmarketing observational studies.

\section{Study population}

The participants in the original PMS were patients with schizophrenia who had psychomotor agitation associated with schizophrenia and had been administered RAIM, as described in detail by Katagiri et al. ${ }^{14}$ The participants who entered to the extension study were decided at physicians' discretion among patients who received oral olanzapine after RAIM administration during the original study period.

Patients were excluded from enrollment if they had contraindications to intramuscular olanzapine in the Japanese package insert, ${ }^{15}$ were specifically in a comatose state, were under the effect of central nervous system depressants, such as barbiturate derivatives, had a medical history of hypersensitivity to any ingredients of intramuscular olanzapine, for example, adrenaline currently used..$^{14}$ In addition to those criteria, oral olanzapine has contraindication to diabetes and history of diabetes in Japan, so patients with them were also excluded from the extension study. ${ }^{16}$

The safety evaluable population included patients who had received both at least one RAIM administration and one oral olanzapine dose. Among those in the safety population, patients who did not receive RAIM and oral olanzapine within each approved (off-label use) indication were excluded from the effectiveness population. Concomitant drug therapies taken during the studies were recorded. Concomitant drug therapy was defined as medication (other than RAIM and oral olanzapine) that was administered from a day before the beginning of the original PMS study to the end of the observational period for the extension study.

\section{Effectiveness}

The PANSS-EC ${ }^{17}$ score was measured at baseline during the original PMS study, and at 2 hours after each administration of RAIM. Additionally, PANSS-EC was measured at 2, 3 (end of the original PMS observational period), and 4 days after the last administration of RAIM. Furthermore, PANSS-EC was measured at day 7 after initial administration (the last day of the extension study period).

\section{Safety}

Safety was assessed by the reporting of TEAEs and adverse drug reactions (ADRs), defined as adverse events for which causal relation to olanzapine could not be excluded. The period of safety assessment was from the first day of RAIM administration (beginning of the original PMS) through the end of the extension study. All TEAEs and ADRs were reported by treating physicians. Recorded TEAEs and ADRs were classified using preferred terms according to the Medical Dictionary for Regulatory Activities (MedDRA Version 19.1; MedDRA MSSO, McLean, VA, USA).

\section{Statistical analysis}

This report includes the results from the beginning of the original PMS study to the end of the extension study, and the baseline of this report is the beginning of the original PMS study. Patient characteristics were summarized by frequency tables with summary statistics. PANSS-EC score was measured at baseline and at each follow-up time point, and changes from baseline to each follow-up time point were assessed using the two-sided 95\% CIs. All statistical analyses were conducted using SAS Version 9.4 (SAS Institute, Cary, NC, USA).

\section{Results \\ Baseline patient characteristics}

A total of 523 case report forms from the 1,016 case reports of the original PMS study ${ }^{14}$ were collected for extension study. The safety analysis set included 522 patients, of whom 521 were included in the effectiveness analysis set. One patient was excluded from the safety analysis set, since the patient's use of intramuscular olanzapine was not clearly confirmed, and one patient was excluded from the effectiveness analysis set due to off-label use. Patients' baseline characteristics are summarized in Table 1. In the 
Table I Baseline patient characteristics and concomitant drug therapies

\begin{tabular}{|c|c|c|}
\hline Characteristics & n (\%) & Mean \pm SD \\
\hline $\mathrm{N}$ & 522 & \\
\hline Age (years) & & $45.9 \pm 15.2$ \\
\hline$<65$ & $446(85.4)$ & \\
\hline$\geq 65$ to $<75$ & $58(I I . I)$ & \\
\hline$\geq 75$ & $18(3.4)$ & \\
\hline \multicolumn{3}{|l|}{ Gender } \\
\hline Male & $248(47.5)$ & \\
\hline Female & $274(52.5)$ & \\
\hline Duration of disease (years) & 371 & $16.6 \pm 13.3$ \\
\hline \multicolumn{3}{|l|}{ History of diabetes in a family member } \\
\hline Absent & $38 \mathrm{I}(73.0)$ & \\
\hline Present & $5(1.0)$ & \\
\hline Unknown & $136(26.1)$ & \\
\hline \multicolumn{3}{|c|}{ Inpatient/outpatient status at the start of treatment } \\
\hline Inpatient & $448(85.8)$ & \\
\hline Outpatient & $74(14.2)$ & \\
\hline Medical history & $40(7.7)$ & \\
\hline Complications & $136(26.1)$ & \\
\hline Diabetes-related complications ${ }^{a}$ & $16(3.1)$ & \\
\hline Concomitant drug therapy ${ }^{\mathrm{b}}$ & $332(63.6)$ & \\
\hline Psychotropic drug & $323(61.9)$ & \\
\hline Antipsychotic & $202(38.7)$ & \\
\hline Mood-stabilizing drug & $67(12.8)$ & \\
\hline Benzodiazepine & $203(38.9)$ & \\
\hline Anticholinergic drug & $66(12.6)$ & \\
\hline Antidepressants & $14(2.7)$ & \\
\hline Others (psychotropic drug) & $50(9.6)$ & \\
\hline Other concomitant drug therapy & $97(18.6)$ & \\
\hline
\end{tabular}

Notes: ${ }^{a}$ Diabetes-related disease complications included high $\mathrm{HbAlc}$ and

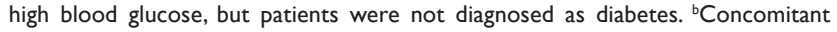
drug therapy was defined as medication (other than rapid-acting intramuscular olanzapine and oral olanzapine) that was administered during the observational period and a day before the observational period. 'Same patients select multiple psychotropic drugs.

Abbreviations: $\mathrm{N}$, total number of patients; $\mathrm{n}$, number of patients.

safety analysis set, the mean age \pm SD was $45.9 \pm 15.2$ years. A total of $446(85.4 \%)$ patients were $<65$ years, $58(11.1 \%)$ patients were $\geq 65$ to $<75$ years, and 18 (3.4\%) patients were $\geq 75$ years of age. A total of 274 (52.5\%) patients were women and $248(47.5 \%)$ were men. The mean \pm SD duration of schizophrenia was $16.6 \pm 13.3$ years. Five $(1.0 \%)$ patients reported having a family member with a history of diabetes, and $16(3.1 \%)$ patients had diabetes-related disease complications (but they were not diagnosed as diabetes). A total of $332(63.6 \%)$ patients reported taking a concomitant drug therapy, with the most common concomitant drug therapies being psychotropic drugs (61.9\%; antipsychotics [38.7\%] and benzodiazepine [38.9\%]). At the initial dose of intramuscular olanzapine, $448(85.8 \%)$ patients were under hospitalization (Table 1).

\section{Olanzapine dose}

The administration patterns were categorized (Figure 1). For pattern 1, 416 patients $(416 / 522,79.7 \%)$ were administered RAIM on day 1 only. For pattern 2, 29 patients (29/522, $5.6 \%$ ) were administered RAIM on days 1 and 2. For pattern 3,63 patients $(63 / 522,12.1 \%)$ were administered RAIM on days 1, 2, and 3. Therefore, most patients were administered RAIM only on the first day (beginning of the original PMS study period).

The $10 \mathrm{mg}$ of RAIM administration accounted for the majority (475/522 patients, $91.0 \%$ ) of patients receiving final administration of RAIM during the original study period. If the patient did not receive oral medication on the final day of RAIM administration, a majority of patients received $10 \mathrm{mg}$ (85/157 patients, $54.1 \%$ ) or $20 \mathrm{mg}$ (37/157 patients, $23.6 \%$ ) of oral olanzapine on the next day after final administration of RAIM. On the other hand, if the patient received oral medication on the final day of administration, a majority of patients receiving the medication on the next day received the same dosage of oral olanzapine as the final day of RAIM administration (eg, when $10 \mathrm{mg}$ of oral olanzapine was used on the last day of RAIM administration, 147/159 [92.5\%] patients took $10 \mathrm{mg}$ of oral olanzapine on the next day; Table 2). Detailed patterns of oral olanzapine dosage after administration of 5 and $20 \mathrm{mg}$ of RAIM are shown in Table S1.

\section{Effectiveness}

The mean \pm SD total PANSS-EC score was 23.6 $\pm 6.2(n=318)$ at baseline (before initial administration of RAIM), 17.4 \pm 6.8 $(\mathrm{n}=280)$ at 2 hours after initial administration, $16.2 \pm 6.8(\mathrm{n}=246)$ 2 days after the final administration, $14.9 \pm 6.2(n=248) 3$ days after the final administration, $13.8 \pm 5.9(n=242) 4$ days after the final administration, $13.2 \pm 5.8(n=221) 7$ days after the initial administration, and $13.4 \pm 6.2(n=351)$ at final observation (with the last observation carried forward approach). The improvement of the total PANSS-EC score that was observed after initial administration of RAIM continued to be maintained after oral olanzapine, through the end of this extension study (Figure 2).

\section{Safety}

Table 3 shows the details of the occurrence of TEAEs and ADRs based on the dose pattern of olanzapine use. The most common TEAEs were dyslalia and somnolence (each event occurred in four patients), and abnormal hepatic function and constipation (occurred in three patients). The most common ADRs were abnormal hepatic function (three patients) and 
Table 2 Oral olanzapine dose after administration of $10 \mathrm{mg}$ on the last day of rapid-acting intramuscular olanzapine

\begin{tabular}{|c|c|c|c|c|c|c|c|c|c|c|c|c|}
\hline \multicolumn{2}{|c|}{$\begin{array}{l}\text { The last day of rapid-acting } \\
\text { intramuscular olanzapine } \\
\text { during the original study } \\
\text { period }\end{array}$} & \multicolumn{11}{|c|}{$\begin{array}{l}\text { Oral olanzapine dose at the next day of rapid-acting intramuscular olanzapine final } \\
\text { administration during the original study period }\end{array}$} \\
\hline $\begin{array}{l}\text { Daily dosage } \\
\text { of rapid-acting } \\
\text { intramuscular } \\
\text { olanzapine }(\mathbf{m g})\end{array}$ & $\begin{array}{l}\text { Oral } \\
\text { olanzapine } \\
\text { daily dose } \\
(\mathbf{m g})\end{array}$ & $0 \mathrm{mg}$ & $2.5 \mathrm{mg}$ & $5 \mathrm{mg}$ & $7.5 \mathrm{mg}$ & $10 \mathrm{mg}$ & $12 \mathrm{mg}$ & $15 \mathrm{mg}$ & $20 \mathrm{mg}$ & $25 \mathrm{mg}$ & $30 \mathrm{mg}$ & Total \\
\hline \multirow[t]{10}{*}{10} & 0 & 17 & 3 & 6 & 3 & 85 & 0 & 4 & 37 & I & I & 157 \\
\hline & 2.5 & 0 & 3 & 0 & 0 & 0 & 0 & 0 & 0 & 0 & 0 & 3 \\
\hline & 5 & 0 & 0 & 33 & 0 & I & 0 & 1 & 1 & 0 & 0 & 36 \\
\hline & 7.5 & 0 & 0 & 0 & 2 & 0 & 0 & 0 & 0 & 0 & 0 & 2 \\
\hline & 10 & 2 & 0 & 0 & 0 & 147 & 0 & 2 & 8 & 0 & 0 & 159 \\
\hline & 12 & 0 & 0 & 0 & 0 & 0 & I & 0 & 0 & 0 & 0 & I \\
\hline & 15 & 0 & 0 & 0 & 0 & I & 0 & 13 & 0 & 0 & 0 & 14 \\
\hline & 20 & 0 & 0 & 0 & 0 & I & 0 & 0 & 101 & 0 & 0 & 102 \\
\hline & 30 & 0 & 0 & 0 & 0 & 0 & 0 & 0 & 0 & 0 & 1 & 1 \\
\hline & Total & 19 & 6 & 39 & 5 & 235 & 1 & 20 & 147 & I & 2 & 475 \\
\hline
\end{tabular}

constipation (three patients). One serious adverse event, sudden cardiac death, occurred during the extension study period (day 6). The patient received oral olanzapine along with many other oral psychotic drugs as concomitant medications. The investigator stated that it was unknown whether or not intramuscular olanzapine and oral olanzapine were related to sudden cardiac death. Also, it was unknown whether or not concomitant medications were related to the event. No particular trend was seen in the occurrence of TEAEs and ADRs, based on the administration pattern.

\section{Discussion}

This report evaluated the effectiveness and safety of oral olanzapine treatment after transitioning from RAIM in patients with acute agitation associated with schizophrenia, in a real-world clinical setting.

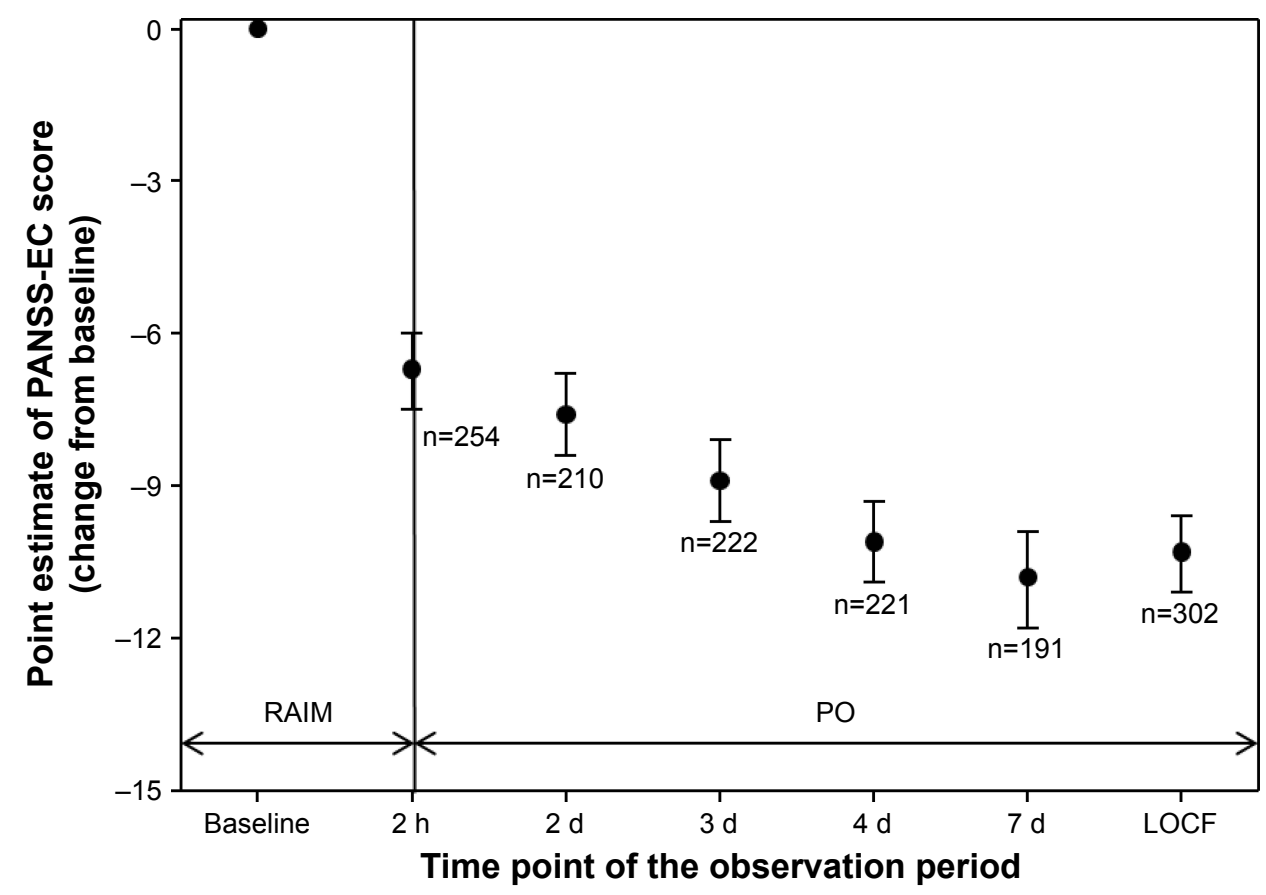

Figure 2 PANSS-EC score.

Note: PANSS-EC score points estimates and $\mathrm{Cl}$ at each time point of the observation period for all patients during the use of RAIM.

Abbreviations: d, days; h, hours; LOCF, last observation carried forward; n, number of patients; PANSS-EC, Positive and Negative Syndrome Scale-Excited Component; $\mathrm{PO}$, Per Os (by mouth, orally); RAIM, rapid-acting intramuscular olanzapine. 
Table 3 TEAEs and adverse drug reactions based on the dose pattern of olanzapine

\begin{tabular}{|c|c|c|c|}
\hline $\begin{array}{l}\text { Dose pattern of } \\
\text { olanzapine use }\end{array}$ & $\begin{array}{l}\text { Days for onset } \\
\text { of TEAEs }\end{array}$ & TEAEs & $\begin{array}{l}\text { Potentially related } \\
\text { to oral olanzapine }\end{array}$ \\
\hline RO-O-O-O-O-O-O & 3 & Constipation & Yes \\
\hline RO-O-O-O-O-O-O & 2 & Abnormal blood glucose & No \\
\hline RO-O-O-O-O-O-O & 6 & Constipation & Yes \\
\hline RO-O-O-O-O-O-O & 2 & Akathisia & Yes \\
\hline \multirow[t]{3}{*}{ RO-O-O-O-O-O-O } & 3 & Dyslalia & Yes \\
\hline & 3 & Tremor & Yes \\
\hline & 3 & Constipation & Yes \\
\hline RO-O-O-O-O-O-O & 1 & Dyslalia & No \\
\hline RO-O-O-O-O-O-O & 2 & Abnormal hepatic function & Yes \\
\hline \multirow[t]{2}{*}{ RO-O-O-O-O-O-O } & 2 & Abnormal hepatic function & Yes \\
\hline & 2 & Renal impairment & Yes \\
\hline RO-O-O-O-O-O-O & 2 & Dyslalia & Yes \\
\hline RO-O-O-O-O-O & 6 & Somnolence & Yes \\
\hline RO-O-O-O-O & 5 & Blood creatine phosphokinase increased & Yes \\
\hline RO-O-O-O & 4 & Neuroleptic malignant syndrome & Yes \\
\hline RO-O-O & 3 & Somnolence & Yes \\
\hline \multirow[t]{10}{*}{ RO-RO-O-O-O } & 2 & Urinary incontinence & No \\
\hline & 3 & Epistaxis & No \\
\hline & 5 & Hemorrhage subcutaneous & No \\
\hline & 5 & Lip hemorrhage & No \\
\hline & 5 & Dysphagia & Yes \\
\hline & 6 & Eye contusion & No \\
\hline & 6 & Ocular hyperemia & No \\
\hline & 6 & Sudden cardiac death & Yes \\
\hline & 6 & Rhinorrhea & Yes \\
\hline & 6 & Salivary hypersecretion & Yes \\
\hline RO-O-RO-O-O-O-O & I & Somnolence & No \\
\hline R-O-O-O-O-O-O & 2 & Abnormal hepatic function & Yes \\
\hline $\mathrm{R}-\mathrm{O}-\mathrm{O}-\mathrm{O}-\mathrm{O}-\mathrm{O}-\mathrm{O}$ & 1 & Dehydration & No \\
\hline \multirow[t]{2}{*}{ R-O-O-O-O } & 2 & Akathisia & Yes \\
\hline & 2 & Dyslalia & Yes \\
\hline R-R-R-O-O-O-O & I & Somnolence & No \\
\hline R-RO-RO-O-O-O-O & 3 & Blood creatine phosphokinase increased & No \\
\hline
\end{tabular}

Note: RO indicates dose pattern of olanzapine use.

Abbreviations: $O$, oral; $R$, rapid-acting intramuscular olanzapine administration; TEAEs, treatment-emergent adverse events.

In this group of patients, the mean PANSS-EC score before initial administration of treatment was 23.6. Previous studies have shown similar PANSS-EC scores when compared to this report, in both a clinical trial setting and in a naturalistic setting, ${ }^{11,18}$ suggesting that patients in these settings had a similar degree of agitation.

Previous studies have reported an improvement in PANSS-EC scores after treatment of acute agitation with intramuscular olanzapine ${ }^{10,11,19,20}$ and after treatment with oral olanzapine. ${ }^{20}$ Our report showed that acute agitation can improve as early as 2 hours after treatment with RAIM, and this improvement was maintained for 7 days after administration of RAIM in patients who transitioned to oral olanzapine. The improvement trend of PANSS-EC seen here was similar to that reported in a previous study during transition from intramuscular to oral therapy, which demonstrated that the combination of intramuscular and oral olanzapine helped to improve treatment of agitation associated with schizophrenia. ${ }^{13}$

A majority of patients received a final administration of $10 \mathrm{mg}$ RAIM. If the patient did not receive oral medication on the final day of RAIM administration, a majority of patients received $10 \mathrm{mg}(54.1 \%)$ or $20 \mathrm{mg}$ (23.6\%) of oral olanzapine the next day after final administration of RAIM. However, if patients received oral medication on the final day of RAIM administration, a majority of patients who received oral olanzapine on the next day received the same dosage (10 mg, 92.5\%; $20 \mathrm{mg}, 99.0 \%$ ) as oral olanzapine on the final day of RAIM administration. We believe that the results presented here from a real-world clinical setting would aid physicians in determining the dose needed for patients using RAIM.

The use of antipsychotics in the treatment of patients with agitation is often associated with occurrence of extrapyramidal 
symptoms. ${ }^{21,22}$ Previous studies have found very rare to no incidences of akathisia in patients treated with intramuscular olanzapine, ${ }^{11}$ and no significant differences in somnolence rates in patients treated with olanzapine compared with placebo. ${ }^{11}$ One study of acutely agitated patients with schizophrenia reported that there were no TEAEs with an incidence of $\geq 10 \%$ for oral olanzapine-treated patients transitioned from RAIM, ${ }^{13}$ whereas another study reported that drowsiness was the most common symptom after treatment with intramuscular or oral olanzapine. ${ }^{20}$ In this report here, the most commonly reported events were dyslalia and somnolence (each event occurred in four patients), and abnormal hepatic function and constipation (occurred in three patients). There did not appear to be any trend leaning toward increasing or worsening the reported adverse events during transition from RAIM to oral olanzapine.

\section{Limitations}

Since there are limitations in this report, it is difficult to conclude the actual effectiveness and safety of olanzapine in patients with agitated schizophrenia who transitioned from RAIM to oral olanzapine treatment. First, since this report was based on observational studies, it is possible that there were many confounding factors, such as variations in baseline characteristics and in the use of concomitant drug therapies among patients, the patient population regarding previous medication, duration of medication, age of onset of the schizophrenia, number of relapses and admissions, other medical comorbidities, and history of other adverse events. Thus, it is possible that the result may be biased due to some missing values. Second, the population in this report included patients who received oral olanzapine on the same day or any day after administration of RAIM during the observational period, so the timing of oral olanzapine treatment is not controlled. Finally, the duration of the observational period was extended but still short, so it is possible that the adverse events following long-term administration of oral olanzapine after transitioning from RAIM may not have been captured.

\section{Conclusion}

This report showed that, in the treatment of acute agitation associated with schizophrenia, RAIM can be transitioned to oral olanzapine without exacerbating psychiatric symptoms or other adverse events and without losing any treatment effect. This finding met the key goal related to rapid management of agitated patients with RAIM while continuing to maintain efficacy after transitioning the treatment to oral olanzapine. This combination of olanzapine may help to improve treatment strategies in patients with acute agitation associated with schizophrenia.

\section{Acknowledgments}

The authors are very grateful to all the physicians of the study sites, the patients and their family members, and other persons who were involved in these studies. Medical writing assistance was provided by Deborah D'Souza, $\mathrm{PhD}$, of inVentiv Health Clinical, LLC, funded by Eli Lilly Japan K.K. These studies were sponsored by Eli Lilly Japan K.K.

\section{Disclosure}

Masanori Taketsuna contributed to this work as a former full-time employee of Eli Lilly Japan K.K. The opinions expressed in this work are solely his own and do not represent his current affiliation (Division of Medical Statistics, Translational Research Informatics Center, Foundation for Biomedical Research and Innovation). All the other authors are employees of Eli Lilly Japan K.K. The authors report no other conflicts of interest in this work.

\section{References}

1. Mohr P, Pecenák J, Svestka J, Swingler D, Treuer T. Treatment of acute agitation in psychotic disorders. Neuro Endocrinol Lett. 2005; 26(4):327-335.

2. Hasan A, Falkai P, Wobrock T, et al. World Federation of Societies of Biological Psychiatry (WFSBP) Guidelines for Biological Treatment of Schizophrenia, part 1: update 2012 on the acute treatment of schizophrenia and the management of treatment resistance. World $J$ Biol Psychiatry. 2012;13(5):318-378.

3. Dahl SG. Pharmacokinetics of antipsychotic drugs in man. Acta Psychiatr Scand Suppl. 1990;358:37-40.

4. Toyoaki H, Sugiyama N. The Japanese Association for Emergency Psychiatry. Guideline, 2015. Chiba: The Japanese Association for Emergency Psychiatry; 2015. Available from: http://www.jaep.jp/ gl/2015_all.pdf. Accessed June 12, 2017.

5. Brook S. Intramuscular ziprasidone: moving beyond the conventional in the treatment of acute agitation in schizophrenia. J Clin Psychiatry. 2003;64 (Suppl 19):S13-S18.

6. Cañas F. Management of agitation in the acute psychotic patientefficacy without excessive sedation. Eur Neuropsychopharmacol. 2007; 17 (Suppl 2):S108-S114.

7. Day JC, Bentall RP, Roberts C, et al. Attitudes toward antipsychotic medication: the impact of clinical variables and relationships with health professionals. Arch Gen Psychiatry. 2005;62(7):717-724.

8. Wright P, Birkett M, David SR, et al. Double-blind, placebo-controlled comparison of intramuscular olanzapine and intramuscular haloperidol in the treatment of acute agitation in schizophrenia. Am J Psychiatry. 2001;158(7):1149-1151.

9. Kishi T, Matsunaga S, Iwata N. Intramuscular olanzapine for agitated patients: a systematic review and meta-analysis of randomized controlled trials. J Psychiatr Res. 2015;68:198-209.

10. Kittipeerachon M, Chaichan W. Intramuscular olanzapine versus intramuscular aripiprazole for the treatment of agitation in patients with schizophrenia: a pragmatic double-blind randomized trial. Schizophr Res. 2016;176(2-3):231-238. 
11. Katagiri H, Fujikoshi S, Suzuki T, et al. A randomized, double-blind, placebo-controlled study of rapid-acting intramuscular olanzapine in Japanese patients for schizophrenia with acute agitation. $B M C$ Psychiatry. 2013;13:20.

12. Breier A, Meehan K, Birkett M, et al. A double-blind, placebocontrolled dose-response comparison of intramuscular olanzapine and haloperidol in the treatment of acute agitation in schizophrenia. Arch Gen Psychiatry. 2002;59(5):441-448.

13. Wright P, Meehan K, Birkett M, et al. A comparison of the efficacy and safety of olanzapine versus haloperidol during transition from intramuscular to oral therapy. Clin Ther. 2003;25(5):1420-1428.

14. Katagiri H, Taketsuna M, Kondo S, Kajimoto K, Aoi E, Tanji Y. Safety and effectiveness of rapid-acting intramuscular olanzapine for agitation associated with schizophrenia - Japan postmarketing surveillance study. Neuropsychiatr Dis Treat. 2018;14:264-272.

15. Zyprexa IntraMuscular Injection [prescribing information]. Kobe: Eli Lilly Japan K.K; 2017. Available from: http://www.info.pmda.go.jp/ go/pack/1179408E1020_1_06/. Accessed March 19, 2018.

16. Zyprexa Tablet for Oral use[prescribing information]. Kobe: Eli Lilly Japan K.K; 2017. http://www.info.pmda.go.jp/go/pack/ 1179044F1029_1_34/. Accessed March 19, 2018.

17. Kay SR, Opler LA, Fiszbein A, Ramirez PM, Opler M, White L. Positive and Negative Syndrome Scale (PANSS) Technical Manual. North Tonawanda, NY: Multi-Health System Inc; 2006.
18. San L, Arranz B, Querejeta I, Barrio S, De la Gándara J, Pérez V. A naturalistic multicenter study of intramuscular olanzapine in the treatment of acutely agitated manic or schizophrenic patients. Eur Psychiatry. 2006; 21(8):539-543.

19. Suzuki H, Gen K, Takahashi Y. A naturalistic comparison of the efficacy and safety of intramuscular olanzapine and intramuscular haloperidol in agitated elderly patients with schizophrenia. Ther Adv Psychopharmacol. 2013;3(6):314-321.

20. Hsu W, Huang SS, Lee BS, Chiu NY. Comparison of intramuscular olanzapine, orally disintegrating olanzapine tablets, oral risperidone solution, and intramuscular haloperidol in the management of acute agitation in an acute care psychiatric ward in Taiwan. J Clin Psychopharmacol. 2010;30(3):230-234

21. Currier GW Simpson GM. Risperidone liquid concentrate and oral lorazepam versus intramuscular haloperidol and intramuscular lorazepam for treatment of psychotic agitation. J Clin Psychiatry. 2001; 62(3):153-157.

22. Brook S, Lucey JV, Gunn KP. Intramuscular ziprasidone compared with intramuscular haloperidol in the treatment of acute psychosis. Ziprasidone I.M. Study Group. J Clin Psychiatry. 2000;61(12):933-941. 


\section{Supplementary material}

Table SI Oral olanzapine dose after administration of 5 and $20 \mathrm{mg}$ on the last day of rapid-acting intramuscular olanzapine

\begin{tabular}{|c|c|c|c|c|c|c|c|c|c|c|c|c|}
\hline \multicolumn{2}{|c|}{$\begin{array}{l}\text { The last day of rapid-acting } \\
\text { intramuscular olanzapine during the } \\
\text { original study period }\end{array}$} & \multicolumn{11}{|c|}{$\begin{array}{l}\text { Oral olanzapine dose at the next day of rapid-acting intramuscular olanzapine final } \\
\text { administration during the original study period }\end{array}$} \\
\hline $\begin{array}{l}\text { Daily dosage of rapid- } \\
\text { acting intramuscular } \\
\text { olanzapine ( } \mathrm{mg})\end{array}$ & $\begin{array}{l}\text { Oral } \\
\text { olanzapine } \\
\text { daily dose (mg) }\end{array}$ & $0 \mathrm{mg}$ & $2.5 \mathrm{mg}$ & $5 \mathrm{mg}$ & $7.5 \mathrm{mg}$ & $10 \mathrm{mg}$ & $12 \mathrm{mg}$ & $15 \mathrm{mg}$ & $20 \mathrm{mg}$ & $25 \mathrm{mg}$ & $30 \mathrm{mg}$ & Total \\
\hline \multirow[t]{9}{*}{5} & 0 & 2 & I & 4 & 0 & 2 & 0 & 0 & 2 & 0 & 0 & II \\
\hline & 2.5 & 0 & 0 & 0 & 0 & 0 & 0 & 0 & 0 & 0 & 0 & 0 \\
\hline & 5 & 0 & 0 & 6 & 0 & 0 & 0 & 0 & 0 & 0 & 0 & 6 \\
\hline & 7.5 & 0 & 0 & 0 & 0 & 0 & 0 & 0 & 0 & 0 & 0 & 0 \\
\hline & 10 & 0 & 0 & 0 & 0 & 5 & 0 & 0 & 0 & 0 & 0 & 5 \\
\hline & 12 & 0 & 0 & 0 & 0 & 0 & 0 & 0 & 0 & 0 & 0 & 0 \\
\hline & 15 & 0 & 0 & 0 & 0 & 0 & 0 & I & 0 & 0 & 0 & I \\
\hline & 20 & 0 & 0 & 0 & 0 & 0 & 0 & 0 & 1 & 0 & 0 & I \\
\hline & 30 & 0 & 0 & 0 & 0 & 0 & 0 & 0 & 0 & 0 & 0 & 0 \\
\hline \multirow[t]{10}{*}{20} & 0 & 5 & 0 & 1 & 0 & 1 & 0 & 0 & 4 & 0 & 0 & II \\
\hline & 2.5 & 0 & 0 & 0 & 0 & 0 & 0 & 0 & 0 & 0 & 0 & 0 \\
\hline & 5 & 0 & 0 & 0 & 0 & 0 & 0 & 0 & 0 & 0 & 0 & 0 \\
\hline & 7.5 & 0 & 0 & 0 & 0 & 0 & 0 & 0 & 0 & 0 & 0 & 0 \\
\hline & 10 & 0 & 0 & 0 & 0 & I & 0 & 0 & 0 & 0 & 0 & I \\
\hline & 12 & 0 & 0 & 0 & 0 & 0 & 0 & 0 & 0 & 0 & 0 & 0 \\
\hline & 15 & 0 & 0 & 0 & 0 & 0 & 0 & 0 & 0 & 0 & 0 & 0 \\
\hline & 20 & 0 & 0 & 0 & 0 & 0 & 0 & 0 & 10 & 0 & 0 & 10 \\
\hline & 30 & 0 & 0 & 0 & 0 & 0 & 0 & 0 & 0 & 0 & I & I \\
\hline & Total & 7 & I & 11 & 0 & 9 & 0 & I & 17 & 0 & I & 47 \\
\hline
\end{tabular}

\section{Publish your work in this journal}

Neuropsychiatric Disease and Treatment is an international, peerreviewed journal of clinical therapeutics and pharmacology focusing on concise rapid reporting of clinical or pre-clinical studies on a range of neuropsychiatric and neurological disorders. This journal is indexed on PubMed Central, the 'PsycINFO' database and CAS and is the official journal of The International Neuropsychiatric Association (INA). The manuscript management system is completely online and includes a very quick and fair peer-review system, which is all easy to use. Visit http://www.dovepress.com/testimonials.php to read real quotes from published authors. 